\title{
Periapikal enfeksiyonun sebep olduğu mental sinirin geçici parestezisi: Olgu sunumu
}

\author{
Mehmet Burak Güneşer ${ }^{1}$
}

Selcuk Dent J, 2016; 3: 135-139

Başvuru Tarihi: 28 Aralık 2016 Yayına Kabul Tarihi: 14 Şubat 2017

\begin{abstract}
Öz
Periapikal enfeksiyonun sebep olduğu mental sinirin geçici parestezisi: Olgu sunumu

Parestezi yanma, karıncalanma, ağrı ve uyuşukluk gibi anormal hislerle tarif edilen duyusal bir rahatsızlıktır. Nadir görülen endodonti ile ilişkili parestezi genellikle büyüyen endodontik lezyonların mental sinire yaptığı lokal baskı ile ilişkilidir. Bu makalede; periapikal enfeksiyonun sebep olduğu mental sinirin geçici parestezisi gelişen bir olgunun, literatür bilgileri ışığında tartışılması amaçlandı. Elli yaşında erkek hastanın alt sağ birinci küçük azı dişten alt sağ dudak ortasına kadar hem ağız içi mukoza hem de yüz bölgesinde parestezi şikayeti bulunmaktaydı. Radyografik incelemede alt sağ birinci küçük azı dişinin apikal bölgesini çevreleyen radyolusent bir lezyon gözlendi. Parestezi endodontik tedavinin başlanmasından sonra 14 gün içinde tamamen çözüldü. Tam iyileşme periapikal cerrahi veya dişin çekimi yerine cerrahi olmayan kök kanal tedavisi ile elde edildi.
\end{abstract}

\section{ANAHTAR KELIMELER}

Cerrahi olmayan endodontik tedavi, parestezi, periapikal lezyon

\section{ABSTRACT}

Temporary paresthesia of the mental nerve induced by periapical infection: Case report

Paresthesia is a sensory disturbance that can be defined as an abnormal sensation such as burning, prickling, pain or numbness. Rarely seen endodontic-related paresthesia is usually associated with the local pressure of enlarged endodontic lesions on the mental nerve. This article aimed to present a case of temporary paresthesia of the mental nerve induced by periapical infection and discuss the case by the light of literature. A 50-year-old man had a complaint of paresthesia on the right side of the lower lip extending from the mandibular midline to the first premolar both extraorally and intraorally in the area of mental nerve stem. Radiographic examination revealed a radiolucent lesion surrounding the apical portion of the right first premolar tooth. The paresthesia was resolved completely within 14 days after the initial of endodontic treatment. The complete healing was obtained only with non-surgical root canal retreatment instead of periapical surgery or tooth extraction.

\section{KEYWORDS}

Nonsurgical endodontic treatment, paresthesia, periapical lesion
Parestezi hastanın sıklıkla yanma, karıncalanma, iğnelenme şeklinde tarif ettiği kısmi uyuşma olarak tanımlanır. Diş hekimliğinde çeşitli lokal ve sistemik faktörler paresteziye neden olmaktadır (Morse 1997). Mandibular blok anestezilerinde kullanılan lokal anestezikler, travma, çene kırıkları, lokal enfeksiyonlar ve neden oldukları baskı, neoplazi, diş çekimi gibi cerrahi müdahaleler ve endodontik tedavi ile ilişkili komplikasyonlar lokal faktörlere örnek olarak verilebilir (Ahonen ve Tjäderhane 2011). Sistemik faktörlerde ise mikrobiyal enfeksiyonlar, multipl skleroz, lenfoma ve diabet bulunmaktadır (Özkan ve ark. 2008). Parestezi etkisinin gün, hafta ve aylarca devam ettiği ve hatta kalıcı olabildiği litearatürde belirtilmiştir (Vasilakis ve Vasilakis 2004, Jerjes ve ark. 2005, Köseoğlu ve ark. 2006, Pelka ve Petschelt 2008, Alves ve ark. 2014). Olguların birçoğunda parestezinin inferior alveoler sinir ve dallarıyla ilişkili olduğu bildirilmiştir (Di Lenarda ve ark. 2000, Yeler ve ark. 2004, Gambarini ve ark. 2011). Periapikal enfeksiyonlarda enflamatuar oluşumun yaptığı mekanik baskı, iskemi ve ayrıca bakterilerin toksik ürünleri mental sinirde paresteziye neden olabilmektedir (Genc Sen ve Kaplan 2015). Bu olgu sunumunda, mental sinir ile ilişkili periapikal enfeksiyonun yol açtığı parestezi olgusunun cerrahi olmayan kanal tedavisi ile iyileştirilmesi ele alınmıştır.

\footnotetext{
${ }^{1}$ Bezmialem Vakıf Üniversitesi Diş Hekimliği Fakültesi Endodonti Anabilim Dalı, İstanbul
} 


\section{OLGU SUNUMU}

Elli yaşında erkek hasta Bezmialem Vakıf Üniversitesi Diş Hekimliği Fakültesi Endodonti Anabilim Dalına alt sağ birinci küçük azı dişten alt sağ dudak ortasına kadar hem ağız içi mukoza hem de yüz bölgesinde ciltte yaklaşık iki haftadır süren hissizlik şikayeti ile başvurdu. Klinik ve radyografik muayenede hastanın alt sağ birinci küçük azı dişinde eski bir restorasyon ve apikalinde radyolusent bir alan olduğu saptandı (Resim 1a). Perküsyon hassasiyeti bulunmayan dişin çevresindeki yumuşak dokunun sağlıklı görünümde olduğu tespit edildi. Elektrikli pulpa testinde dişten cevap alınamazken simetriği ve komşu dişlerden pozitif cevap alındı.

Ekstraoral ve introral muayenenin ardından yüzeyel duyuların değerlendirilmesi işlemine geçildi. Hastanın gözleri kapatılarak toplu iğnenin sivri ve künt kısmı yüz bölgesinde cilde temas ettirildi. Aynı işlem simetrik bölgeye uygulanarak kontrolü yapıldı ve hastaya hissedip hissetmediği soruldu. Dokunma duyusunun muayenesinde yine hastanın gözleri kapatılarak ufak bir pamuk yavaşça ilgili alana dokundurularak yapıldı. $\mathrm{Bu}$ işlemler sonrası hastada alt dudağın orta hattından alt sağ çenede foramen mentaleye kadar olan kısımda hem mukoza hem de cilt yüzeyini kapsayacak şekilde dokunma ve duyusal his kaybı olduğu tespit edildi.

İlgili dişin apikalindeki lezyonun lokalizasyonu ve mandibular kanalla ilişkisinin değerlendirilmesi amacıyla Konik Işınlı Bilgisayarlı Tomografi (CBCT) alındı (Planmeca Promax 3D Mid, Helsinki, Finlandiya). Kesitlerin değerlendirilmesi sonucunda alt sağ birinci küçük azı dişin apikalinde linguale doğru genişleyen büyük bir radyolusent lezyon izlendi. Dişin apikali çevresindeki lezyonun foramen mentale ile yakın ilişkisi belirlendi (Resim 2).
Herhangi bir sistemik ve medikal rahatsızlığı bulunmayan hastanın alt sağ birinci küçük azı dişine kronik apikal periodontitis teşhisi konularak kanal tedavisine başlandı. Eski restorasyon kaldırıldı ve çürük temizlendi. Endodontik giriş kavitesi hazırlandıktan sonra lastik örtü (rubber dam) ile dişin izolasyonu sağlandı. Eksuda çıkışı gözlenmeyen kanal öncelikle \% $2.5 \mathrm{NaOCl}$ (Wizard; Rehber Kimya, İstanbul, Türkiye) ile yıkandı ve ardından çalışma boyu 15 numara K-tipi bir kanal aleti (Dentsply Maillefer, Ballaigues, İsviçre) ve elektronik apeks bulucu (Root ZX mini, J Morita Co, Tustin, CA, ABD) yardımıyla belirlendi. Ardından çalışma boyu dijital radyografi ile teyit edildi. Kök kanalı ProTaper Universal döner alet eğeleri ile F5 (çap 50, 0.06 taper) eğesine kadar şekillendirildi. Yapılan biyomekanik preparasyonun ardından smear tabakasının çıkarılması için kanal \% $2.5 \mathrm{NaOCl}$ ve \% 17 EDTA (Wizard; Rehber Kimya, İstanbul, Türkiye) solüsyonları ile yıkandı. Son yıkama solüsyonu olarak klorheksidin (Klorhex, Drogsan, Türkiye) kullanılmasının ardından kanala akıcı kıvamda kalsiyum hidroksit (Sultan Chemists Inc., Englewood, NJ, ABD) bir lentülo yardımıyla yerleştirildi. Kanal ağzına ufak bir pamuk pelet yerleştirilmesinin ardından diş cam iyonomer siman (Ketac Molar, 3M ESPE, Seefeld, Almanya) ile geçici restore edildi. Hastaya post operatif ağrı durumuna karşı günlük iki tablet flurbiprofen türevi analjezik (Majezik $100 \mathrm{mg}$ ) ve parestezi çözülene kadar kullanması için günlük 1 tablet B12 vitamini (Benexol® B12) reçete edildi.

Bir hafta sonra verilen randevuda alt sağ birinci küçük azı dişinin asemptomatik olduğu belirlendi. Hasta parestezinin 4.günden sonra çözülmeye başladığını belirtti. Kanal dolgusu gütta perka (Diadent Group,
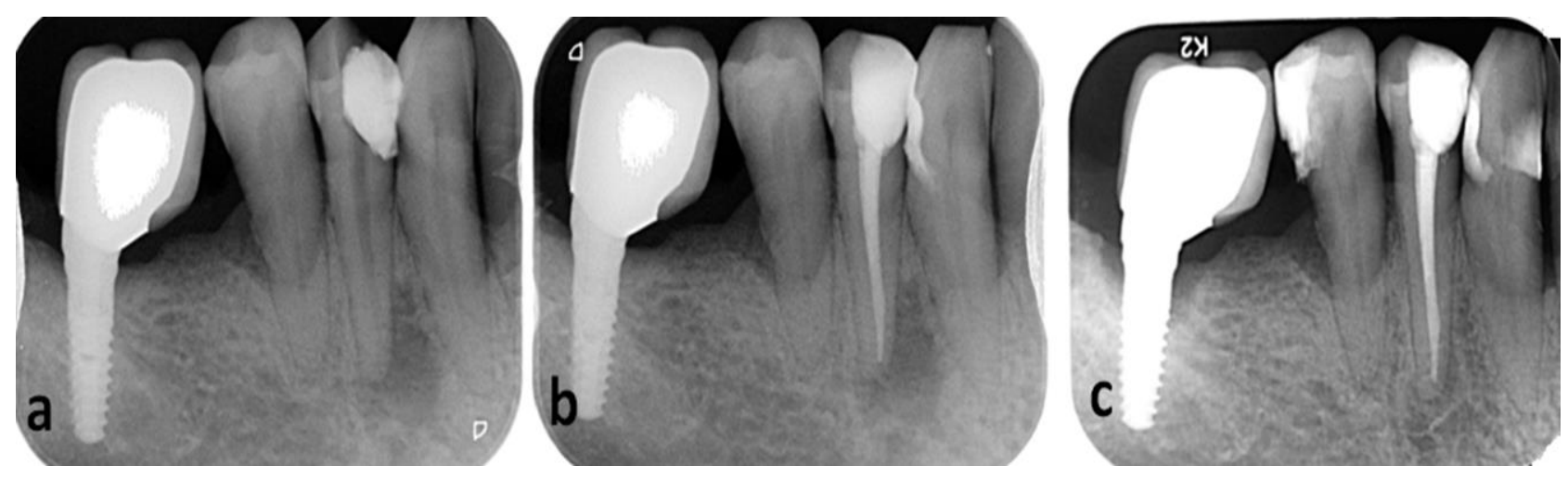

Resim 1.

a) Alt sağ birinci küçük azı dişin teşhis radyografisi

b) Alt sağ birinci küçük azı dişin kanal tedavisi tamamlandıktan sonraki radyografisi

c) Alt sağ birinci küçük azı dişin kanal tedavisinin tamamlanmasından yaklaşık 3 yıl sonra alınan kontrol radyografisi 


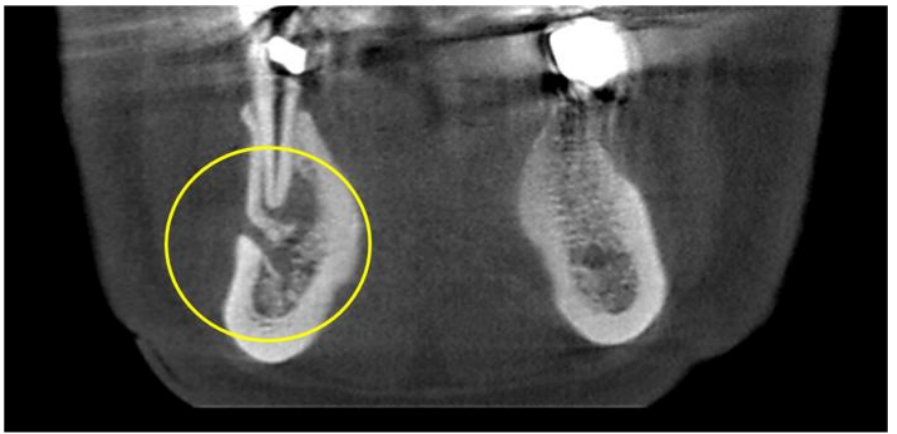

Resim 2

Alt çeneden alınan CBCT görüntüsü (koronal kesit)

Seul, Kore) ve AH plus patı (Dentsply DeTrey, Zürih, İsviçre) ile dolduruldu (Resim 1b). Daimi restorasyonu hibrit kompozit kullanılarak tamamlandı (Filtek Z250, 3M ESPE). Hastada parestezi kanal tedavisine başlanmasından 2 hafta sonra tümüyle ortadan kalktı.

Yaklaşık üç yılın sonunda alınan kontrol radyografisinde radyolusent lezyonun kaybolarak periapikal iyileşmenin, kemik ve lamina dura oluşumunun tamamlanmasıyla sağlandığı tespit edildi (Resim 1c). Diş asemptomatik olup radyografik olarak herhangi bir patoloji göstermeden hala fonksiyon göstermektedir.

\section{TARTIŞMA}

Parestezinin teşhisi için uygun anamnez, etkilenen bölgeye nosiseptif veya mekanoseptif testlerin uygulanması, periapikal ve panaromik radyografiler ve bazı durumlarda CBCT alınması oldukça önemlidir (Gambarini ve ark. 2011, Genc Sen ve Kaplan 2015). Paresteziye yol açan etkenin türü, oluşan hasarın boyutu ve semptomların görülmesinden bu yana geçen süreye bağlı olarak uygun bir tedavi yöntemi belirlenmelidir (Jerjes ve ark. 2005). Tedavi sonrası düzenli kontrol randevuları kadar hastanın parestezinin iyileşme süreci hakkında bilgilendirilmesi ve endişelerinin giderilmesi de gerekmektedir (Ahonen ve Tjäderhane 2011).

Nörotoksik materyallerin mandibular sinir kanalına kaçırılması durumunda sinir hasarının kalıcı olmaması için yabancı materyalin periapikal bölgeden 48 saatten daha kısa sürede cerrahi olarak uzaklaştırılması gerekmektedir (Pogrel 2007). Hatta dişin çekimi ve yabancı materyalin uzaklaştırımasının bile gerektiği durumlar söz konusu olabilmektedir (Pogrel 2007). Taşkın çalışma, taşkın kanal dolgusu, endodontik materyallerin inferior alveloer sinir ve dallarının komşu olduğu alanlara taşırıması endodontik tedavi ile ilişkili parestezi sebepleri arasında sayılabilir (Vasilakis ve Vasilakis 2004). Endodontik materyallerden kaynaklı parestezi olgularında başarıya ulaşmada komplikasyon sonrası geçen sürenin yanı sıra taşkın materyalin cinsi, taştığı yer ve miktarı gibi durumlar da oldukça önemlidir (Köseoğlu ve ark. 2006).
$\mathrm{Bu}$ olguda mevcut implantın da böyle bir paresteziye yol açabileceği akla gelse de hasta implant uygulanması sürecinde belirtilerden bahsetmemiş ve öncelikle saptanan etkenin ortadan kaldırılması hedeflenmiştir. Lokal enfeksiyonlardan kaynaklı parestezi olgularında genellikle kök kanal tedavisi veya periapikal cerrahi ile enfeksiyonun giderilmesi yeterli olmaktadır (Yeler ve ark. 2004). Periapikal granülom, radiküler kist veya adenokarsinom gibi alt çenede görülen metastatik tümörler alt dudağı da içeren parestezilere yol açabilmektedir (Jerjes ve ark. 2005). Bu gibi olgularda parestezinin kalıcı olmaması için mümkün olan en kısa sürede müdahale oldukça önemlidir (Morse 1997, Pogrel 2007). Parestezi olgularında lezyon ile sinirin yakın ilişkisinden dolayı endodontik tedavi gibi konservatif yaklaşımlar öncelikli olmalıdır; ancak gerek görülürse cerrahi yaklaşımlardan da kaçınılmamalıdır. Çünkü mekanik ve kimyasal irritanların uzaklaştırılamaması sinir fibrillerinin daha fazla dejenarasyonunu ve böylece parestezinin kalıcı olma ihtimalini artırmaktadır (Ahonen ve Tjäderhane 2011).

Paresteziden en çok etkilenen iki sinir inferior alveoler sinir ve mental sinirdir (Di Lenarda ve ark. 2000). Bu olgu sunumunda görülen parestezinin en olası sebebinin periapikal lezyonun inferior alveroler sinir ve mental sinire yaptığı mekanik baskı ve ayrıca bakterilerin toksik metabolik ürünleri olduğu düşünülmektedir. Özellikle alt küçük azı dişler ile foramen mentalenin yakın ilişkisi nedeniyle bu dişlerde endodontik tedaviyle ilişkili komplikasyonlardan kaynaklı parestezi görülmektedir (Ngeow 2010). CBCT ile alınan görüntüler dişlerin kök kanal morfolojisi, köklerin maksiller sinüs ve mandibular sinir gibi anatomik yapılara yakınlığı ve periapikal lezyonun kök ile ilişkisi hakkında geleneksel radyografilerle karşılaştırıldığında daha detaylı bilgiler sunmaktadır (Gambarini ve ark. 2011). Bu olguda CBCT alınmasının sebebi teşhis amaçlı çekilen panaromik ve periapikal radyografilerde apikal lezyonun büyüklüğü ve foramen mentale ile olan yakın ilişkisinin tam anlamıyla detaylandırılamayışıdır. Ayrıca hastanın olası sinir hasarına bağlı gerçekleşen parestezi ile ilgili haklı endişeleri nedeniyle daha detaylı radyolojik inceleme için CBCT alındı. Tedavi sonrası CBCT alınmamasının nedeni klinik iyileşmenin kısa sürede gerçekleşip periapikal radyografide iyileşmenin takip edilebilmesi ve hastanın gereksiz radyasyon almaması içindir.

Enfeksiyon kaynaklı mental sinir parestezilerinde uygun endodontik tedavi veya cerrahi yaklaşım 
parestezinin çözülmesinde yeterli olmaktadır. Literatürde etken ortadan kaldırılığında parestezinin birkaç gün/hafta içinde çözüldüğünü bildiren olgu sunumları mevcuttur. Örneğin Morse (1997) alt birinci küçük azı dişindeki enfeksiyon kaynaklı mental sinir parestezili bir olguda kanal tedavisi, antibiyotik ve deksamatazon ile tedavi sonrasında parestezinin yedi hafta içinde çözüldüğünü bildirmiştir. Genç Şen ve Kaplan (2015) alt ikinci küçük azı dişindeki periapikal enfeksiyonun yol açtığı mental sinir parestezisinin geleneksel antibiyotik destekli endodontik tedavi ile sekiz hafta içinde çözüldüğünü rapor etmiştir. Ahonen ve Tjäderhane (2011) alt ikinci küçük azı dişinden kaynaklanan mental sinir parestezili olguda dişteki kanal tedavisinin yenilenmesi sonrasında parestezinin tümüyle çözülmesinin yaklaşık bir seneyi bulduğunu belirtmiştir. Di Lenarda ve ark. (2000) periapikal lezyonlu alt birinci küçük azı dişinin kanal tedavisini takiben 14 gün içinde parestezinin tümüyle çözüldüğünü bildirmiştir.

\section{SONUÇ}

Mental sinirden kaynaklı parestezi olgularına çok sık rastlanmasa da parestezinin önemi göz ardı edilmemelidir. Bu olgu sunumunda cerrahi yaklaşıma gerek kalmadan yalnızca kök kanal tedavisine başlanarak mental sinir parestezisi 2 hafta içinde tamamen çözülmüştür. Kök kanallarının dezenfeksiyonu gerçekleştirilerek enfeksiyon ve enflamasyonun ortadan kaldırılması ve iyileşmeye bağlı olarak lezyonun sinire yaptığı mekanik baskının azalmasının parestezinin çözülmesindeki en önemli etken olduğu düşünülmektedir. 


\section{KAYNAKLAR}

Ahonen M, Tjäderhane L, 2010. Endodontic-related paresthesia: a case report and literature review.J Endod, 37, 1460-4.

Alves FR, Coutinho MS, Gonçalves LS, 2014 Endodontic-related facial paresthesia: systematic review. J Can Dent Assoc, 80, e13.

Di Lenarda R, Cadenaro M, Stacchi C, 2000. Paresthesia of the mental nerve induced by periapical infection: a case report. Oral Surg Oral Med Oral Pathol Oral Radiol Endod, 90, 746-9.

Gambarini G, Plotino G, Grande NM, Testarelli L, Prencipe M, Messineo D, Fratini L, D'Ambrosio F, 2011, Differential diagnosis of endodontic-related inferior alveolar nerve paraesthesia with cone beam computed tomography: a case report. Int Endod J, 44, 176-81.

Genc Sen O, Kaplan V, 2015. Temporary Mental Nerve Paresthesia Originating from Periapical Infection. Case Rep Dent, 2015, 457645.

Jerjes W, Swinson B, Banu B, Al Khawalde M, Hopper C, 2005. Paraesthesia of the lip and chin area resolved by endodontic treatment: $A$ case report and review of literature. Br Dent J, 198, 743-5.

Köseoğlu BG, Tanrikulu S, Sübay RK, Sencer $S$, 2006. Anesthesia following overfilling of a root canal sealer into the mandibular canal: a case report. Oral Surg Oral Med Oral Pathol Oral Radiol Endod, 10, 803-6.

Morse DR, 1997. Infection-related mental and inferior alveolar nerve paresthesia: literature review and presentation of two cases. J Endod, 23, 457-60.

Ngeow WC, 2010. Is there a "safety zone" in the mandibular premolar region where damage to the mental nerve can be avoided if periapical extrusion occurs? J Can Dent Assoc ,76, a61.

Ozkan BT, Celik S, Durmus E, 2008. Paresthesia of the mental nerve stem from periapical infection of mandibular canine tooth: a case report.Oral Surg Oral Med Oral Pathol Oral Radiol Endod, 105, 28-31.

Pelka M, Petschelt A, 2008. Permanent mimic musculature and nerve damage caused by sodium hypochlorite: a case report.Oral Surg Oral Med Oral Pathol Oral Radiol Endod, 106, e80-3.
Pogrel MA, 2007. Damage to the inferior alveolar nerve as the result of root canal therapy. J Am Dent Assoc, 138, 65-9.

Vasilakis GJ, Vasilakis CM, 2004. Mandibular endodontic-related paresthesia. Gen Dent, 52, 334-8.

Yeler H, Ozeç I, Kiliç E, 2004. Infection-related inferior alveolar and mental nerve paresthesia: case reports. Quintessence Int, 35, 313-6.

Yazışma Adresi:

Yrd. Doç. Dr. Mehmet Burak GÜNEŞER

Bezmialem Vakıf Üniversitesi

Diş Hekimliği Fakültesi

Endodonti A.D.

İstanbul, Türkiye

E-mail: bguneser@hotmail.com 